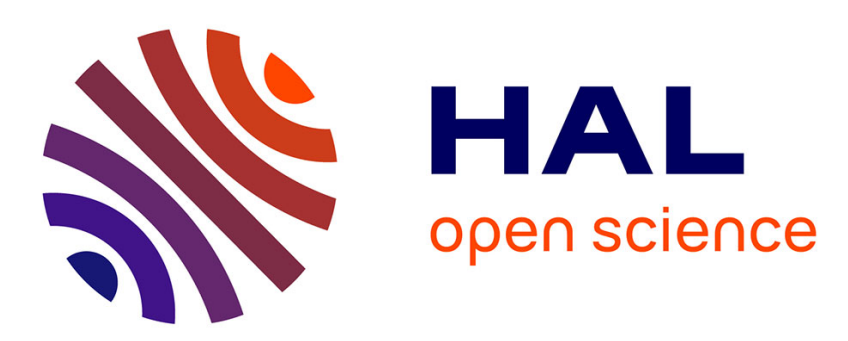

\title{
Compared stress tolerance to short-term exposure in native and invasive tunicates from the NE Atlantic: when the invader performs better
}

\author{
Joseph M. Kenworthy, Dominique Davoult, Christophe D Lejeusne
}

\section{To cite this version:}

Joseph M. Kenworthy, Dominique Davoult, Christophe D Lejeusne. Compared stress tolerance to short-term exposure in native and invasive tunicates from the NE Atlantic: when the invader performs better. Marine Biology, 2018, 165 (10), pp.1-11/164. 10.1007/s00227-018-3420-1 . hal-01922822

\section{HAL Id: hal-01922822 \\ https://hal.science/hal-01922822}

Submitted on 16 Jan 2019

HAL is a multi-disciplinary open access archive for the deposit and dissemination of scientific research documents, whether they are published or not. The documents may come from teaching and research institutions in France or abroad, or from public or private research centers.
L'archive ouverte pluridisciplinaire HAL, est destinée au dépôt et à la diffusion de documents scientifiques de niveau recherche, publiés ou non, émanant des établissements d'enseignement et de recherche français ou étrangers, des laboratoires publics ou privés. 
1 Compared stress tolerance to short term exposure in native and invasive tunicates from the NE

2 Atlantic: when the invader performs better

3 Joseph M. Kenworthy, Dominique Davoult and Christophe Lejeusne*

4 Address: Sorbonne Université, CNRS, Adaptation et Diversité en Milieu Marin AD2M

5 UMR 7144, Station Biologique de Roscoff, Place Georges Teissier CS90074, 29688 Roscoff,

6 France.

$7 \quad *$ corresponding author

$8 \quad$ Email: christophe.lejeusne@sb-roscoff.fr

$9 \quad$ Telephone: $+33(0) 298292372$ 


\section{Abstract}

11 The combined impact of invasive species and climate change threatens natural systems worldwide,

12 often facilitating the expansion of harmful invasive species. It is imperative to understand the

13 mechanisms behind why species become invasive and widespread. Traditionally, it is thought that

14 invasive species have greater tolerances to a wider array of environmental conditions than natives. We

15 therefore tested the hypothesis that invasive species are more tolerant to the effects of short term

16 exposure to temperature and salinity stress. Using unifactorial experiments, we compared the

17 tolerances of two common fouling NE Atlantic ascidians, the native Ciona intestinalis and the

18 invasive Styela clava, to increased temperature and decreased salinity. We measured lethal and

19 behavioural responses affecting $50 \%$ of populations to give an indication of the tolerance limits for

20 temperature $\left(\mathrm{LT}_{50}\right)$ and salinity $\left(\mathrm{EC}_{50}\right)$, and respiration rate to give an indication of the change in

21 metabolic response. The invasive $S$. clava was more tolerant to increased stress $\left(\mathrm{LT}_{50}=29.5^{\circ} \mathrm{C}, \mathrm{EC}_{50}\right.$

$22=19.5)$ compared with $C$. intestinalis $\left(\mathrm{LT}_{50}=27.0^{\circ} \mathrm{C}, \mathrm{EC}_{50}=22.7\right)$, whereas both species displayed

23 similar metabolic responses observed through increased respiration rates. This study is among the first

24 to experimentally determine limits for temperature and hyposalinity stress for either species and

25 supports the hypothesis that the invader performs better under extreme conditions. Future environmental changes caused by events such as heatwaves and climate change could push species to

27 the edge of their physiological limits, potentially facilitating competitive shifts between native and invasive species. 


\section{Introduction}

On a global scale the impact of invasive species is paramount, causing detrimental ecological impacts to ecosystems and their native communities (Mack et al. 2000; Butchart et al. 2011). In combination with climate change, the impacts of invasive species threaten biodiversity worldwide, potentially causing wide ranging effects. These include: impacting native species abundances and distributions; local extinctions; alteration of vital ecosystem functions and services; and significant economic impacts (Pimentel et al. 2005; Halpern et al. 2008; Hellmann et al. 2008; Pejchar and Mooney 2009; Butchart et al. 2011). Furthermore, these two drivers of change often interact with climate change enhancing the spread of non-native species (Dukes and Mooney 1999; Hellmann et al. 2008).

Evidence supports the hypothesis that shipping and hull fouling is a major vector in transporting marine species worldwide (Clarke Murray et al. 2012; Peters et al. 2017). What is less clear is the mechanisms employed by invasive species to enable them to become so pervasive. Generally, for invasive species perceived higher physiological tolerances to a range environmental conditions (e.g. temperature, salinity, pollution levels) is thought to enable greater competitive ability over native species, helping to facilitate successful settlement, establishment of populations, and further spread (Lenz et al. 2011; Zerebecki and Sorte 2011; Lejeusne et al. 2014; Lagos et al. 2017).

Invasive species often cause serious detrimental impacts. Of the biofouling taxa, tunicates are a major concern. They can cause smothering of aquaculture facilities and species, damage to structures, increased drag on propellers resulting in reduced efficiencies, and significant cleaning costs (Aldred and Clare 2014). For example, the highly invasive tunicate Styela clava presents a significant global risk. Its introduction in the Gulf of St Lawrence, Canada, resulted in a 50\% loss to shellfish aquaculture industries (Colautti et al. 2006). In the present study we therefore address the tolerance of S. clava in comparison to the NE Atlantic native tunicate Ciona intestinalis, which is also considered invasive in other parts of the world and causes significant economic impacts (e.g. Colautti et al. 2006; Therriault and Herborg 2008a). It is imperative that we understand the physiological mechanism behind these species invasion success. 
Recently C. intestinalis has undergone taxonomic re-evaluation. Formerly at least two cryptic species, Types A and B, made up this species complex and are now known as $C$. robusta and $C$. intestinalis respectively (Brunetti et al. 2015). C. robusta prefers warmer waters, is native to north-west Pacific and is introduced worldwide including Europe. Conversely, C. intestinalis is considered a cold water species native to north-western Europe, from northern Portugal to Norway (Bouchemousse et al. 2016a). This species is also considered invasive in China (Zhan et al. 2010) and the north-eastern American coastline (Therriault and Herborg 2008b). However, recent genetic evidence suggests an amphi-Atlantic native distribution (Bouchemousse et al. 2016a). Prior to taxonomic re-evaluation this species was considered to tolerate temperatures exceeding $30{ }^{\circ} \mathrm{C}$ (Dybern 1965; Marin et al. 1987; Carver et al. 2006); however the highest temperature tolerances were attributed to specimens found in the Mediterranean where C. robusta is pervasive (Zhan et al. 2010). So virtually no information is available on the tolerance of $C$. intestinalis to thermal stress. Similarly, previous data regarding the salinity tolerance of this species should be carefully interpreted considering taxonomic re-evaluation. Generally $C$. intestinalis is considered a euryhaline species and, among populations within this species native range, it has been observed to tolerate salinities under 12 (Dybern 1967; Carver et al. 2006).

By contrast $S$. clava is native to the north-west Pacific but has spread worldwide including to Europe, North America and Australasia (Lützen 1999; Davis and Davis 2008). Within these locations its settlement is known to result in significant economic impacts to aquaculture; in Canada alone this was estimated between CA\$34-88 million per year (Colautti et al. 2006). Within Europe it was first recorded in 1953 (designated as Styela mammiculata) in the Lynher Estuary, Plymouth, UK (Carlisle 1954). It then started expanding across north-western Europe during the following decades (Lützen 1999) and was first recorded in the Mediterranean by the mid 2000's (Davis and Davis 2008). Major vectors of this spread can be attributed to human mediated transport on ship hulls and within ballast water whereas natural dispersion is responsible for spread to neighbouring sites only (Davis et al. 2007). Experimental and observational studies of specimens located outside of this species native range show that $S$. clava settles in locations experiencing temperatures ranging from $-2{ }^{\circ} \mathrm{C}$ to in excess of $23{ }^{\circ} \mathrm{C}$ (Buizer 1980; Davis and Davis 2008). However, there is limited evidence to suggest its 
maximum tolerance. In addition, these studies have also indicated a preference for warm waters, showing that for successful reproduction and settlement of this species ambient water temperatures must exceed $16{ }^{\circ} \mathrm{C}$ for several days (Davis et al. 2007). This species also has limited osmoregulation capabilities, preferring salinities above 20 (Davis et al. 2007; Davis and Davis 2008). However it has been known to survive lower salinities by closing siphons for prolonged periods (Sims 1984; Lützen 1999).

Understanding the tolerance of species to environmental conditions is key to understanding their potential spread. Regarding the two species of interest here, while they are common in urbanised habitats, often dominating fouling communities (Lambert and Lambert 1998; Gittenberger and Van Der Stelt 2011), their tolerance to temperatures and salinities is not widely understood, particularly with regard to the metabolic impacts of these stressors. Furthermore, the recent taxonomic reevaluation of $C$. intestinalis calls to question previous evidence of tolerance for this species. We therefore conducted a series of short term ( 24 hour) experiments examining the impact of increased temperatures and decreased salinities on S. clava and C. intestinalis, evaluating survival and metabolic response in terms of respiration. These were used to determine upper temperature and lower salinity tolerance limits. These limits are known to be strongly correlated with the range of conditions a species would be expected to be able to tolerate under natural conditions (Zerebecki and Sorte 2011; Kelley 2014); therefore, these upper limits give an indication of the capacity of these species to be able to survive extreme conditions. We hypothesised that the invasive $S$. clava would display a greater tolerance to short term hyposalinity and increased temperature in comparison to the native $C$. intestinalis, both in terms of survival and metabolic response.

\section{$\underline{\text { 2. Methodology }}$}

\subsection{Collection and maintenance of organisms}

Ciona intestinalis and Styela clava were collected from the Château Marina in Brest, France $\left(48^{\circ} 22^{\prime} 44^{\prime \prime} \mathrm{N}, 4^{\circ} 29^{\prime} 21^{\prime \prime} \mathrm{W}\right)$ in June 2017 . Seawater temperature was continually monitored at 3 locations within the marina using HOBO (UA-002-64) data loggers, deployed between the 26 March 

- 4 October 2017 and attached to floating structures (Supplementary material). Individuals were found in high abundances attached to artificial substrates (pontoons, ropes, metal pillars). Species were collected from under pontoons by SCUBA diving, carefully scraping and removing adults from structures located within the centre of the marina. Organisms were subsequently transported to the Roscoff Biological Station in seawater where they were cleaned of epiphytes and epibionts and placed overnight in running ambient temperature seawater aquariums. Specimens were then transferred into controlled temperature tanks with renewed seawater inflow for long term storage. Based upon water conditions from which they were taken and temperatures appropriate to maintain live animals, specimens were kept at $16^{\circ} \mathrm{C}$. Every two days specimens were fed a 1:2 (by cell count) mixture of the algae Chaetoceros gracilis (IFREMER strain from Argenton) and Isochrysis galbana (Tahitian strain from Roscoff Culture Collection) totalling approximately 4 x $10^{8}$ cells $\mathrm{L}^{-1}$. All specimens were acclimated to these conditions for at least 72 hours prior to experimentation.

\subsection{Experimental setup}

The same experimental procedure was used for both the temperature and salinity experiments. During each experiment, experimental units (EU's) consisted of 2 individuals of a single species placed in a $1.8 \mathrm{~L}$ tank supplied with constant aeration. In total each experiment used 40 EU's -2 species x 5 treatments (levels of salinity or temperature) $\mathrm{x} 4$ replicates for each treatment-species combination. This equated to 4 EU's per treatment per species which were spread among 5 large temperaturecontrolled aquaria (Figure 1); the heaters used maintained temperature $\pm 0.5^{\circ} \mathrm{C}$ from the target.

After 24 hours each EU was assessed for mortality based upon the number of live and dead individuals within the tank ( $\mathrm{n}=4$ EU's per treatment per species). In addition, 1 individual was removed from each EU to measure respiration. Hence 4 individuals were used per treatment per species for respiration $(n=4)$. Specimens used in the respiration measurements were selected based upon their visual size: approximately 5-8 $\mathrm{cm}$ for $C$. intestinalis and 8-11 $\mathrm{cm}$ for $S$. clava. To determine mortality 3 criteria were assessed: contraction (siphon or body), colour change, and loss of response to gentle touching of the siphons. 


\subsection{Temperature experiment}

Temperature treatments were as follows: 16 (control: stock tank temperature), 20, 24,28 and $32{ }^{\circ} \mathrm{C}$.

Desired temperatures were achieved by raising the water temperature within the 5 large temperaturecontrolled aquaria (Figure 1). After placing individuals within tanks and starting from $16^{\circ} \mathrm{C}$, temperatures were raised by $1{ }^{\circ} \mathrm{C}$ every 15 minutes. Once the desired temperature was reached tanks were left for 24 hours.

$16^{\circ} \mathrm{C}$

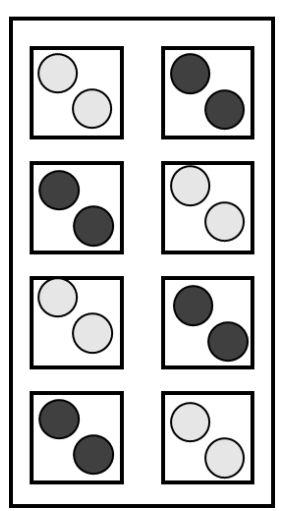

$20^{\circ} \mathrm{C}$

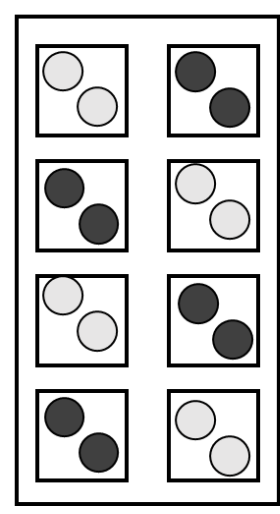

$24^{\circ} \mathrm{C}$

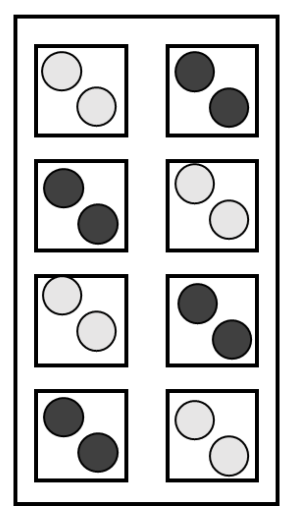

$28^{\circ} \mathrm{C}$

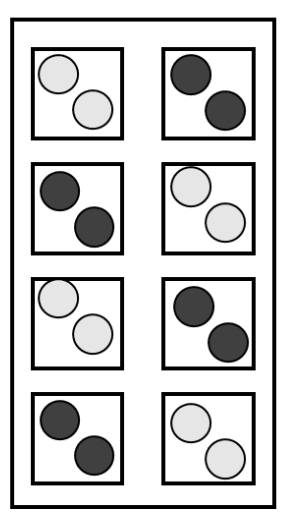

$32^{\circ} \mathrm{C}$

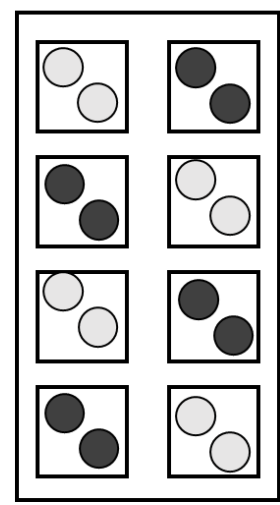

Figure 1: Experimental setup of the temperature experiment. Each experimental unit (EU; small square) contains 2 individual specimens of the same species (circles; Ciona intestinalis $=$ light grey, Styela clava $=$ dark grey). EUs are placed inside larger temperature-controlled tanks (large rectangle) filled with freshwater to homogenise and maintain the temperature within each EU over the 24 hour experimental duration.

To assess respiration acrylic incubation chambers $(600 \mathrm{ml})$ were utilised using methods from Noisette et al. (2016). Each chamber was filled with seawater that was equilibrated to the same temperature used in the corresponding treatment. One individual from each EU was taken and placed in a single chamber ( $\mathrm{n}=4$ per treatment per species). A magnetic stirrer was placed within each chamber and the chambers were positioned on a waterproof stirring plate. The plate was kept underwater in an additional temperature-controlled aquarium, equilibrated to the corresponding treatment temperature. The stirring plate allowed 6 chambers to be incubated simultaneously. In addition, 6 control chambers were used for each temperature to correct for fluxes due to microbial activity within the seawater in each of the treatments. Using a fibre-optics system and reactive oxygen spots on the chambers (FIBOX 3, PreSens, Regensburg, Germany), oxygen was measured at the start and end of an incubation period which lasted for 30 minutes. Respiration ( $\mathrm{R}$; in $\mu \mathrm{mol} \mathrm{O}_{2} \mathrm{~g}^{-1} \mathrm{DW} \mathrm{hr}{ }^{-1}$ ) was calculated using the following equation: 


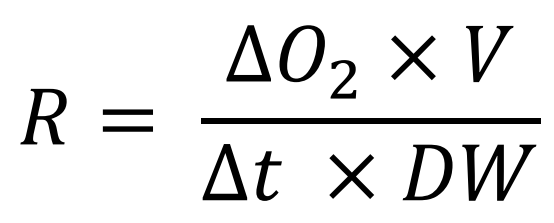

158 where $\Delta \mathrm{O}_{2}$ (in $\mu$ mol $\left.\mathrm{O}_{2} \mathrm{~L}^{-1}\right)$ is the difference in oxygen concentration between the start and end of the

159

160

161

162

163

164

165

166

167 incubation, $\mathrm{V}$ is the measured volume of each chamber minus the volume of the specimen, $\Delta \mathrm{t}$ is the incubation time (hours), and DW is the dry weight ( $\mathrm{g}$ ) of the specimen and obtained by placing specimens in a drying oven for 48 hours at $60^{\circ} \mathrm{C}$.

\subsection{Salinity experiment}

To obtain the desired salinities distilled water was added to seawater and checked using a Fisher Scientific ${ }^{\mathrm{TM}}$ Traceable ${ }^{\mathrm{TM}}$ salinometer. Salinity treatments were as follows: 35 (control: natural seawater), 28, 24, 21 and 17 . The lower values were chosen based upon the ranges of salinity tolerance observed in other studies (Shumway 1978; Carver et al. 2006; Clarke and Therriault 2007; Davis et al. 2007) and on pilot studies where mortalities occurred between salinities of 14-21. Each EU contained 2 individuals which were placed directly from natural seawater into altered salinity water. EU's were randomly dispersed amongst the 5 large temperature-controlled aquaria to prevent fluctuations in temperature over the experimental duration.

This experiment was independent from the temperature experiment and used different apparatus for calculating oxygen concentration. The experimental setup follows the methodology used in the temperature experiment, the differences being the chambers used for incubation and the device used to measure oxygen within the water. The equation for calculating respiration remains the same. In this experiment, incubations were conducted within hermetically sealed glass chambers of two sizes (200 $\mathrm{ml}$ and $500 \mathrm{ml}$ ). Due to the smaller $C$. intestinalis used in this experiment, a smaller size of incubation chamber $(200 \mathrm{ml})$ was necessary to allow an appreciable change in oxygen to be able to calculate respiration accurately. This chamber was too small for S. clava which was therefore incubated in the larger (500 ml) chamber. Oxygen was measured using an oxygen probe (Hach-Lange LDO101) prior 
to sealing the chambers (incubation start) and following the incubation (approximately 30 minutes), at which point the seal was broken and the oxygen measured immediately.

\subsection{Data analysis}

Mortality data were used to calculate the temperature that was lethal to $50 \%$ of the population ( $\left.\mathrm{LT}_{50}\right)$.

For the salinity experiments, at the range used, a behavioural response was observed rather than a mortal response; the effective concentration $\left(\mathrm{EC}_{50}\right)$ was therefore calculated and defined as the salinity at which $50 \%$ of individuals displayed a response. Binomial regression models using the probit link function were used to model the response and to produce mortality curves. Using these models, the $\mathrm{LT}_{50}$ and $\mathrm{EC}_{50}$ and corresponding confidence intervals were calculated. All analyses were completed using the statistical programme R, version 3.22 (R Core team 2015) and visualised using the ggplot2 package (Wickham, 2009).

Two-factor ANOVA was used to analyse the respiration data, which, depending on the experiment, used either the temperature or salinity and species as fixed factors. To facilitate a balanced statistical design in the temperature experiment, the highest temperatures $\left(28\right.$ and $\left.32{ }^{\circ} \mathrm{C}\right)$ were not included in the analysis due to high mortality. To explore interaction terms and explore the impact of temperature on individual species (thus incorporating excluded data for higher temperatures where data were available), single factor ANOVA and Tukey's HSD posteriori comparisons (where appropriate) were performed for each species. Residuals of the model were checked for normality and homogeneity of variances; the salinity data set was log transformed to meet normality and homogeneity of variances criteria.

\section{Results}

\subsection{Temperature experiment}

After 24 hours increased temperatures had a significant effect on the mortality of both Ciona intestinalis and Styela clava (Figure 2A); in both species 100\% mortality occurred within the highest temperature treatment $\left(32^{\circ} \mathrm{C}\right)$. There was a small difference in the modelled $\mathrm{LT}_{50}$ values observed in 
205

206

207

208

209

210

211

212

213

214

215

216

217

218

219

both species. The invasive $S$. clava displayed higher tolerance to increased temperatures $\left(\mathrm{LT}_{50}=29.5\right.$ $\left.{ }^{\circ} \mathrm{C} ; \mathrm{CI}=27.1-31.9\right)$ than the native $C$. intestinalis $\left(\mathrm{LT}_{50}=27.0{ }^{\circ} \mathrm{C} ; \mathrm{CI}=25.5-28.5\right)$.

In the analysis of respiration (Table 1), there was no significant interaction term between species and temperature treatments indicating respiration in both species was affected similarly by increased temperatures. Overall respiration was significantly lower in $S$. clava compared to $C$. intestinalis. Temperatures above $16{ }^{\circ} \mathrm{C}$ resulted in the highest respiration for both species (Figure 2B). There was $100 \%$ mortality at $32{ }^{\circ} \mathrm{C}$, and only 1 surviving $C$. intestinalis at $28{ }^{\circ} \mathrm{C}$ on which respiration could be measured, therefore only the first 3 temperature treatments were considered in the two factor ANOVA (Table 1). Increased temperatures resulted in significantly higher respiration in comparison to the $16^{\circ} \mathrm{C}$ temperature treatment. There were no differences between the measured respiration at $20{ }^{\circ} \mathrm{C}$ and $24{ }^{\circ} \mathrm{C}$ for C. intestinalis, nor at $28^{\circ} \mathrm{C}$ in S. clava (Figure 2B).

\section{Table 1: Two-factor ANOVA examining the effects of temperature (A) and salinity (B) on two species of ascidian - the} native Ciona intestinalis and the invasive Styela clava - using species and the stressor (either temperature or salinity) as fixed factors. Effects of temperature were examined at 3 levels $\left(16,20\right.$ and $\left.24{ }^{\circ} \mathrm{C}\right)$ and salinity at 5 levels $(17,21,24,28$ and 35). Bold type indicates a significant effect at $\mathrm{p}<0.05 ; \mathrm{n}=4$ for all treatments.

\begin{tabular}{|c|c|c|c|c|c|}
\hline A) Temperature & Factor & df & MS & $\boldsymbol{F}$ & $\mathbf{p}$ \\
\hline & Temperature & 2 & 636.1 & 27.13 & $<0.001$ \\
\hline & Species & 1 & 126.9 & 5.41 & 0.031 \\
\hline & Temperature $x$ Species & 2 & 10.1 & 0.43 & 0.656 \\
\hline & Residuals & 19 & 23.4 & & \\
\hline \multirow[t]{5}{*}{ B) Salinity } & Factor & df & MS & $\boldsymbol{F}$ & $\mathbf{p}$ \\
\hline & Salinity & 4 & 0.6 & 4.07 & 0.009 \\
\hline & Species & 1 & 3.99 & 27.17 & $<0.001$ \\
\hline & Salinity $x$ Species & 4 & 0.15 & 1.01 & 0.416 \\
\hline & Residuals & 30 & 0.15 & & \\
\hline
\end{tabular}


A

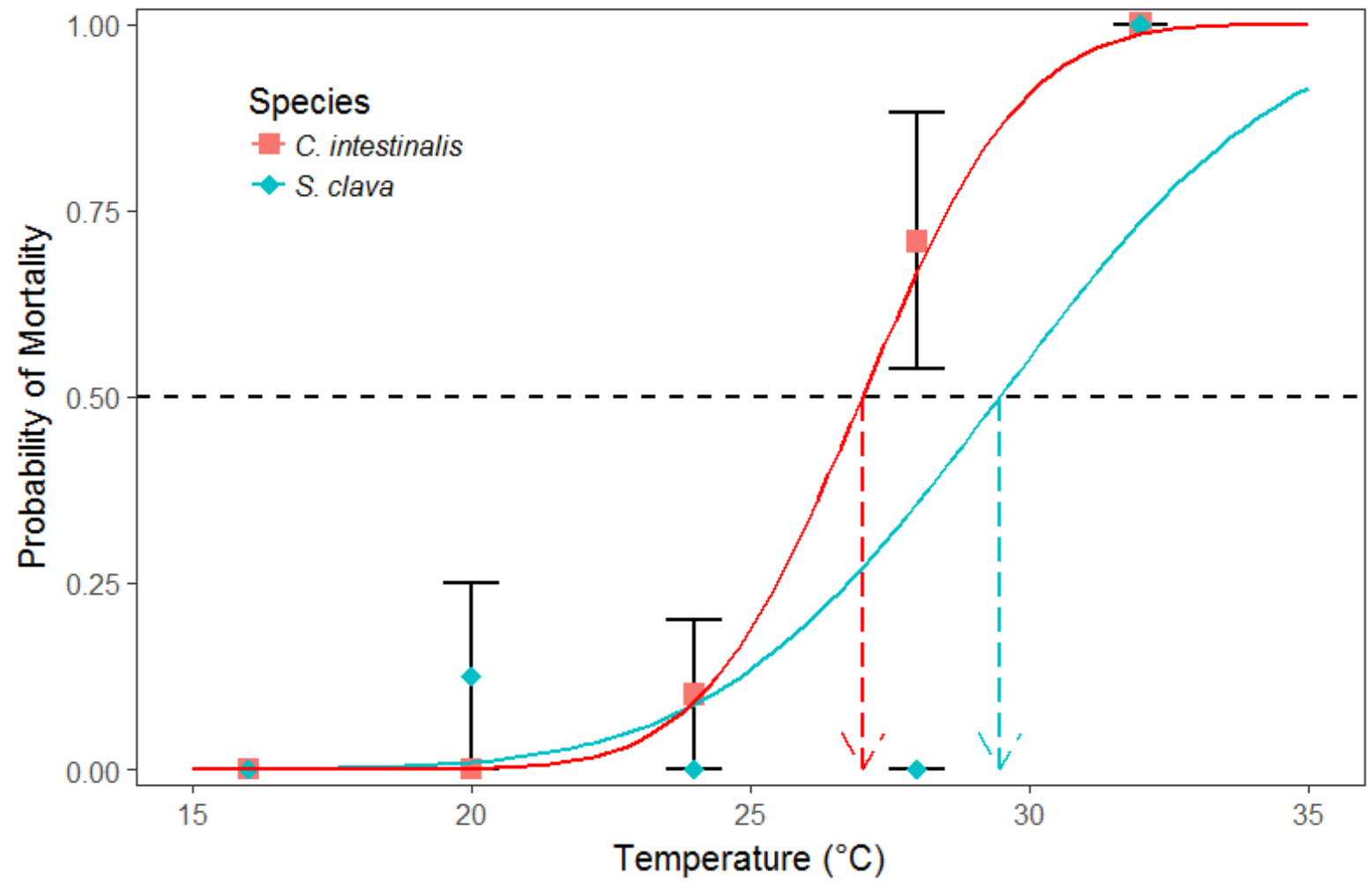

B

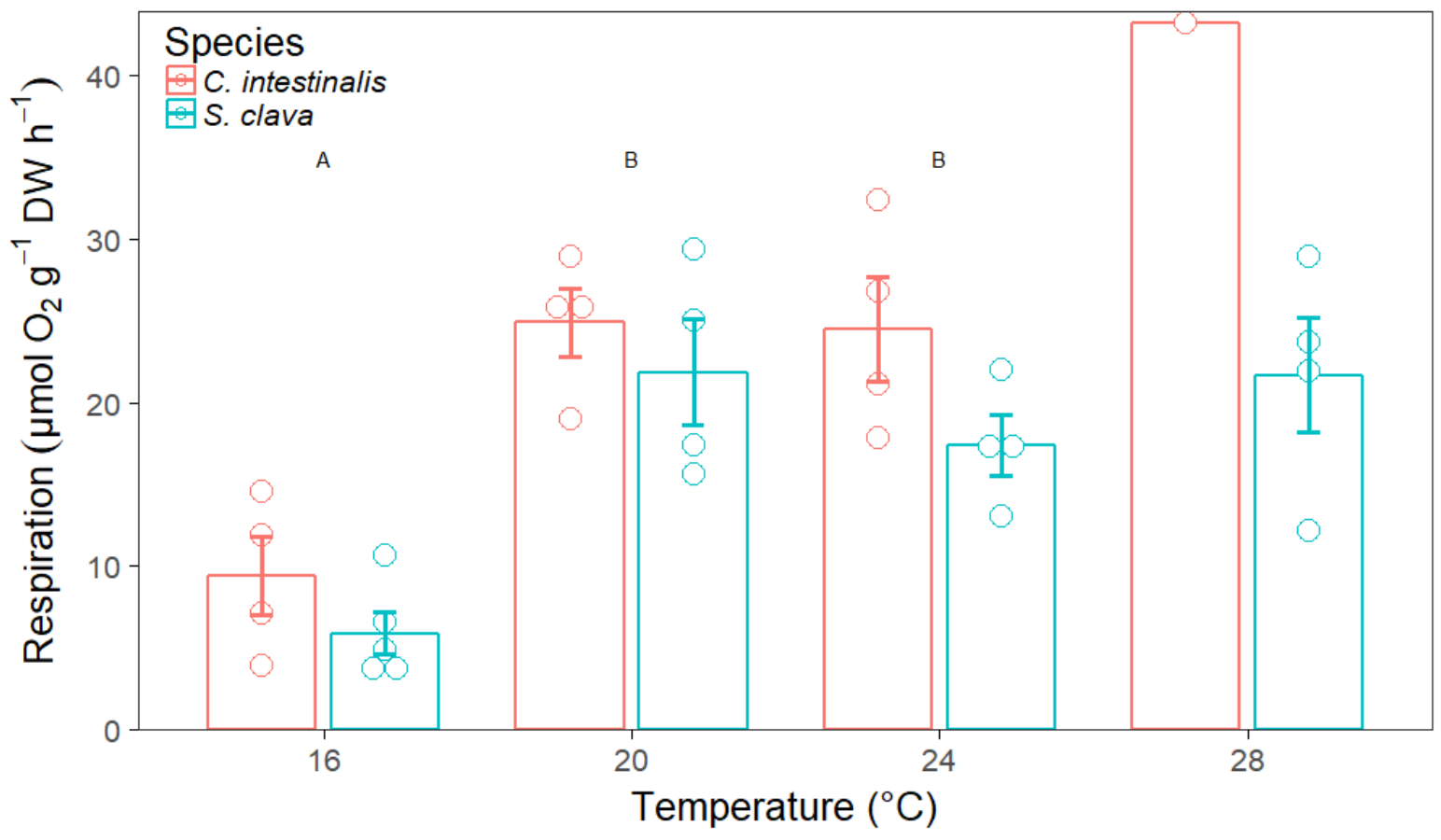

224 Figure 2: - A) Mean probability of mortality $( \pm \mathrm{SE})$ and $\mathrm{B})$ respiration $\left(\mu \mathrm{mol} \mathrm{O} \mathrm{g}^{-1}\right.$ dry weight $\left.\mathrm{h}^{-1}\right)$ of Ciona intestinalis and

225 Styela clava exposed to increased temperatures for 24 hours $(\mathrm{n}=4)$. Mortality curves $($ A) were produced using Probit

226 analysis and indicate the probability of a species mortality at a given temperature; $50 \%$ mortality is indicated for each

227 species $\left(\mathrm{LT}_{50}\right)$. For respiration $(\mathrm{B})$, bars represent mean respiration $( \pm \mathrm{SE})$ and circles are individual data points, as within the 
ANOVA there were significant main effects, letters indicate significant differences within the temperature factor only, as determined by posteriori analyses $\left(28^{\circ} \mathrm{C}\right.$ was not included in the analysis due to lack of replication).

\subsection{Salinity experiment}

231 There was a minimal effect of lowered salinities on mortality at the ranges tested. Only 2 specimens

232 were clearly identified as dead, meeting all 3 criteria of mortality as defined in the methodology.

233 There was, however, a behavioural response whereby specimens no longer responded to touching

234 their siphons. In addition to being unresponsive, the siphons of S. clava specimens were continually

235 open (not contracted), whereas in $C$. intestinalis specimens were extremely contracted. Therefore, in

236 the following analysis, this behavioural response has been modelled, calculating the effective salinity

237 impacting $50 \%$ of the population $\left(\mathrm{EC}_{50}\right)$.

238 Both species displayed a tolerance to decreased salinities, however after 24 hours all individuals in the

239 lowest salinity treatment displayed the described behavioural response (Figure 3A). S. clava displayed

240 the greatest tolerance to decreased salinity with an $\mathrm{EC}_{50}$ of $19.5(\mathrm{CI}=17.3-21.6)$ whereas $C$.

241 intestinalis displayed an $\mathrm{EC}_{50}$ of $22.7(\mathrm{CI}=21.6-23.8)$.

242 Within the two factor model analysing the impacts of salinity on respiration (Table 1), there was no

243 significant interaction term, while the main effects were significant. Within the salinity experiment

244 there was a large difference in respiration rates observed between the two species. Similarly to the

245 temperature experiment, overall higher respiration by body mass was observed in C. intestinalis.

246 Salinity had a significant effect on both species (Table 1) whereby respiration rate was lower in

247 natural seawater (salinity 35) in comparison to salinities less than 28 (Figure 3B). 
A

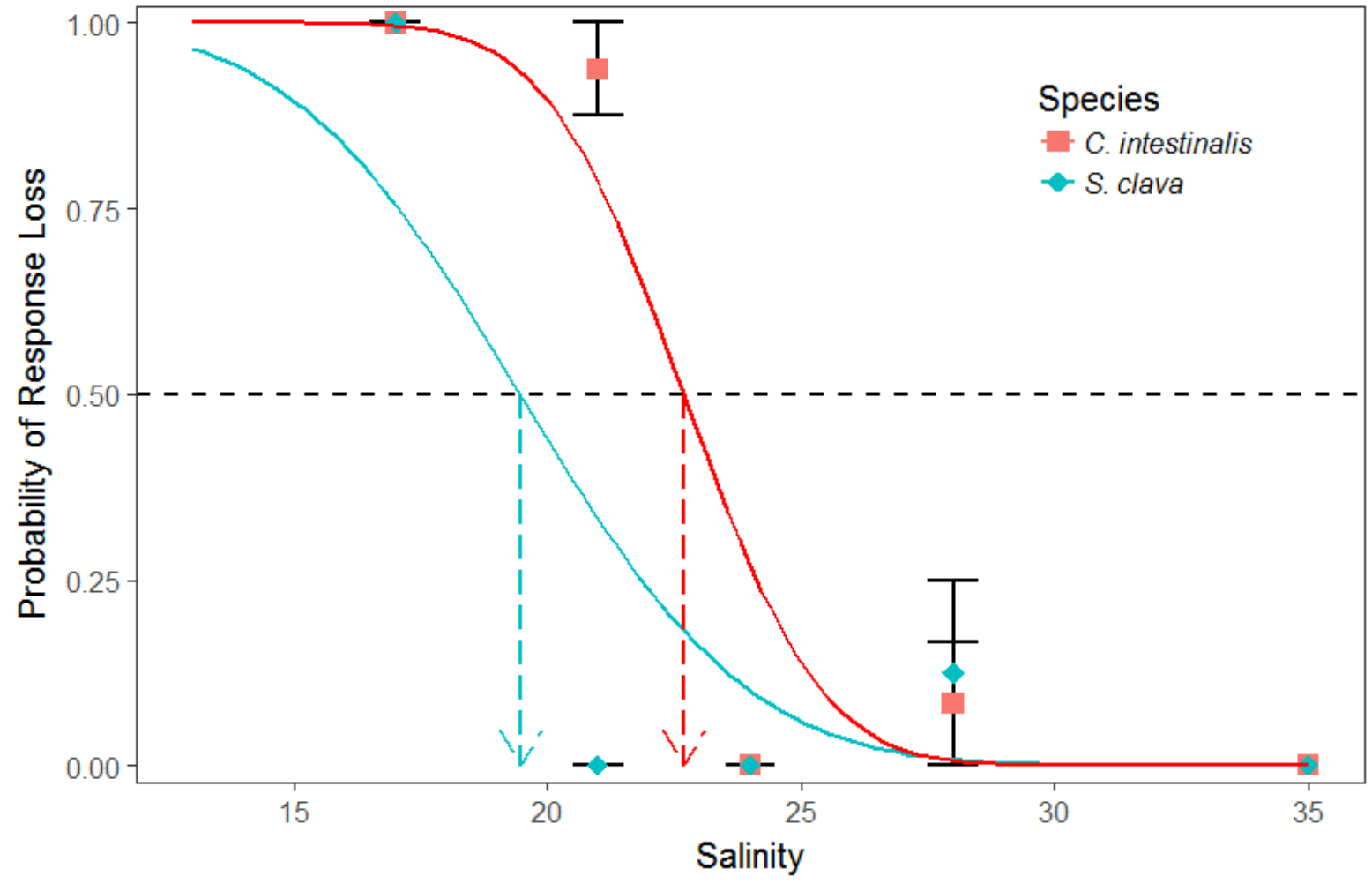

B

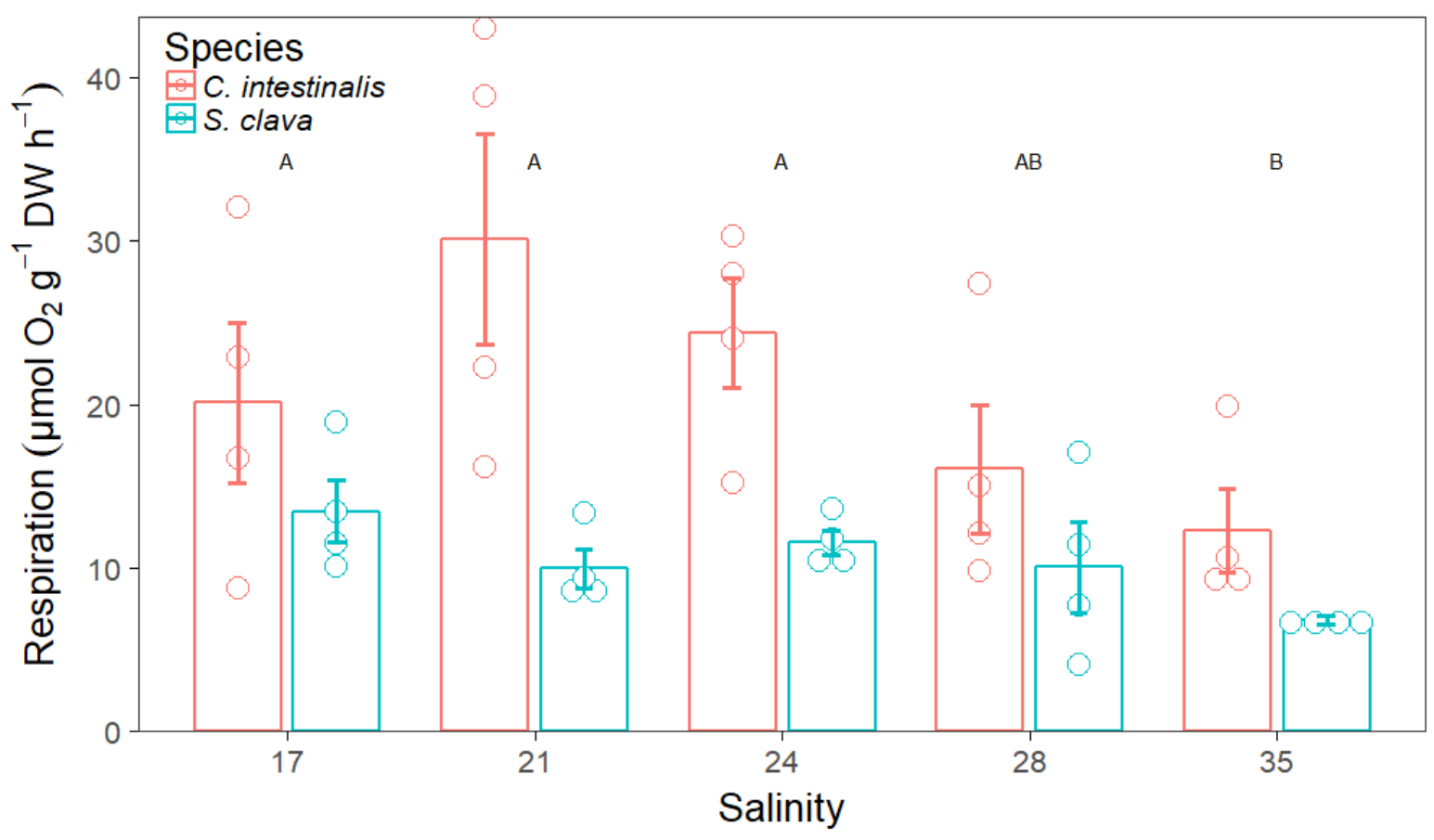

251 Figure 3: A) Mean probability of the loss of response $( \pm \mathrm{SE})$ and $\mathrm{B})$ respiration $\left(\mu \mathrm{mol} \mathrm{O} \mathrm{g}^{-1}\right.$ dry

252 weight $\left.\mathrm{h}^{-1}\right)$ of Ciona intestinalis and Styela clava exposed to decreased salinities for 24 hours $(\mathrm{n}=4)$.

Response curves (A) were produced using Probit analysis and indicate the probability of a species 
losing responsiveness to stimuli at a given salinity; $50 \%$ of the populations response loss is indicated for each species $\left(\mathrm{EC}_{50}\right)$. For respiration $(\mathrm{B})$, bars represent mean respiration $( \pm \mathrm{SE})$ and circles are individual data points, as within the ANOVA there were significant main effects, letters indicate significant differences within the salinity factor, as determined by posteriori analyses.

\section{Discussion}

In experiments examining the tolerance of two common fouling species to increased temperatures and decreased salinities, the invasive Styela clava and the native Ciona intestinalis both displayed high tolerances to short term (24 hours) exposure. Comparatively, while in both species the respiration rates responded similarly to the altered salinities or temperatures, $S$. clava displayed tolerances greater than that of $C$. intestinalis in terms of displaying mortal $\left(\mathrm{LT}_{50}\right)$ and behavioural responses $\left(\mathrm{EC}_{50}\right)$. This is in agreement with other studies stating invasive species have a wider tolerance range which, among other responses, impact survival and respiration (Lenz et al. 2011; Zerebecki and Sorte 2011;

Lejeusne et al. 2014). Worldwide both species are commonly found fouling urbanised habitats such as marinas and are considered invasive species (Davis and Davis 2008; Zhan et al. 2010). As such, human-induced dispersal and climate change influencing temperature and salinities have the potential to influence worldwide distribution patterns and range expansions of these species (De Rivera et al. 2011; Rius et al. 2014). This study offers empirical evidence of the versatility of these ascidians, particularly regarding S. clava which is a highly prolific invader. This species was shown to tolerate a wide range of environmental conditions, therefore facilitating its spread and the threat of future invasion success.

\subsection{Thermal tolerance}

In the mortality analysis, the invasive $S$. clava was able to tolerate and survive at higher temperatures than the European Atlantic native $C$. intestinalis $\left(\mathrm{LT}_{50}=29.5^{\circ} \mathrm{C}\right.$ and $27^{\circ} \mathrm{C}$ respectively). In terms of the respiratory response, both species were affected similarly by increased temperature. This complements previous experimental studies documenting that invasive species temperature tolerances are greater than those of comparative native species (Zerebecki and Sorte 2011; Kelley 2014; 
Lejeusne et al. 2014). Furthermore, we empirically show upper temperature limits to acute thermal stress $\left(\mathrm{LT}_{50}\right)$, providing information on each species thermal niche. Higher upper thermal tolerance limits are known to be a strong indicator of the eurythermality of a species (Kelley 2014). When assessing multiple species, these upper limits can therefore give a good indication of comparative tolerances of species, thus relating to how species would cope with environmental changes in the wild. Based on geographic ranges, $C$. intestinalis is documented to be found in temperatures ranging from subzero to up to $24^{\circ} \mathrm{C}$ (Dybern 1965; Carver et al. 2006; Vercaemer et al. 2011). However, the recent taxonomic separation of $C$. intestinalis (previously $C$. intestinalis type B) from its congener $C$. robusta (type A) calls to question tolerance experiments conducted prior to its separation. By comparison, previous monitoring has shown that $S$. clava typically establishes invasive populations in locations where temperatures range from subzero to in excess of $23{ }^{\circ} \mathrm{C}$ (Buizer 1980; Davis and Davis 2008), however there is less information on a maximum temperature for this species. In an example of known populations where sea surface temperatures have exceeded these limits, Davis and Davis (2010) noted that in Sète, French Mediterranean, extreme summer temperatures reached $29.1{ }^{\circ} \mathrm{C}$ in 2006. While this is only slightly lower than the $\mathrm{LT}_{50}$ we observed here, the survival of this population in Sète was originally theorised to be due to refuge habitats at lower (and cooler: $26.6{ }^{\circ} \mathrm{C}$ ) depths (Davis and Davis 2010). We show that $S$. clava could survive these extreme events, at least for the short term.

The IPCC predicts that climate change is expected to increase global temperatures worldwide by between $1-3.7{ }^{\circ} \mathrm{C}$ by the end of the century (IPCC 2013) and increase the severity of summer heatwaves by up $2{ }^{\circ} \mathrm{C}$ in the coming decades (Meehl 2004; Perkins-Kirkpatrick and Gibson 2017). Extreme summer temperatures have already been shown to significantly impact subtidal communities (Lejeusne et al. 2010; Sorte et al. 2010; Smale et al. 2015). With increasing severity, the observed effects will become more pronounced. At present, in the Château Marina in Brest, France, we observed maximum summer water temperatures of $21^{\circ} \mathrm{C}$ and the summer averages approximately 18 ${ }^{\circ} \mathrm{C}$ (Supplementary material). Future increases in temperature will likely impact fouling communities 
306

307

308

309

310

311

312

313

314

315

316

317

318

319

320

321

322

323

324

325

326

327

and could potentially impact invasive and native species differently based upon their respective tolerances (Sorte et al. 2010; Smale et al. 2015).

With respect $S$. clava and C. intestinalis, it is likely that temperatures up to or exceeding the $\mathrm{LT}_{50}$ for both species could be detected within Europe by the end of the $21^{\text {st }}$ century. This could have significant impacts on the range of $S$. clava, causing it to become an even more ubiquitous invader in European waters and worldwide. Already we are seeing this species moving further north (e.g. Cook et al. 2013) but there is potential for it to spread to new locations around the Iberian Peninsula and the Mediterranean (Davis and Davis 2010; Çinar 2016). While ocean warming could facilitate the spread of $S$. clava, the native $C$. intestinalis is a cold water species and its hypothetical range expansion due to climate change would be more limited. At present $C$. intestinalis is dominant within Brittany where this species occurs in syntopy with $C$. robusta. It is known that warmer summers in these locations tend to facilitate increased settlement of the invasive C. robusta (Bouchemousse et al. 2016b) and monitoring suggests $C$. intestinalis has a much lower thermal maxima and is less tolerant to thermal changes than $C$. robusta (see Bouchemousse et al. 2016a, b). With respect to climate change, increased temperatures could impact physiological mechanisms and result in higher mortality in $C$. intestinalis, thus decreasing its competitive ability over $C$. robusta and resulting in a competitive shift between the two species. Given that the tolerance of native species tends to be lower than taxonomically similar invasive species (Lenz et al. 2011; Lejeusne et al. 2014), other species will likely be impacted similarly to increased temperatures and result in significant community shifts.

While the survival data relate to thermal maxima, a functional stress response can be observed for both species at lower temperatures. This directly relates to the tolerance of a species and its potential to become an invader outside of its native range. For both species, the rates of respiration increased when temperatures exceeded $20^{\circ} \mathrm{C}$, where it reached its maximum. At temperatures above $20{ }^{\circ} \mathrm{C}$, there were zero or negligible increases in respiration rate. Similar results were observed by Ai-Li et al. (2008) and Kang et al. (2015) who confirm this relationship is consistent among size classes of $S$. clava. Similar results have also been observed on other physiological responses in C. intestinalis. For example in populations from Denmark, Petersen and Riisgård (1992) discovered that filtration rates 
333

334

335

336

337

338

339

340

341

342

343

344

345

346

347

348

349

began to decline above $21^{\circ} \mathrm{C}$, whereas at lower temperatures, a linear relationship between filtration rate and increasing temperature was observed. This suggests thermal stress was occurring above these temperatures and complements the present study where a metabolic response is observed and peaks at $20^{\circ} \mathrm{C}$. At higher temperatures, there were no further significant changes in respiration rate however given that there was high mortality in our treatments above $24^{\circ} \mathrm{C}$, it is reasonable to suggest temperature is causing a significant stress response, at least for $C$. intestinalis.

In this study, no further increases in metabolic response over $20{ }^{\circ} \mathrm{C}$ indicates a reduction in temperature-dependency of the metabolism (i.e. at higher temperatures metabolism is not impacted by increasing temperature). While this could be interpreted as an indication that the animal is stressed, measurement of multiple physiological mechanisms should be regarded to fully consider an organism's ability to survive or grow (e.g. scope for growth model: Warren and Davis 1967; Newell and Branch 1980). In other studies of temperature effects on various physiological mechanisms employed by S. clava, temperatures above $24{ }^{\circ} \mathrm{C}$ have resulted in declines of feeding and excretion rates, and temperatures of $28{ }^{\circ} \mathrm{C}$ have been shown to cause declining function and scope for growth (Jiang et al. 2008; Kang et al. 2015). However, even within this temperature range, S. clava has been shown to be well adapted, with the capacity to maximise its physiological response according to temperature to meet energy demands (Jiang et al. 2008). The higher tolerance displayed by S. clava and other invasive species is perhaps one of the most significant features that allow them to spread and establish worldwide.

\subsection{Hyposalinity tolerance}

Our results correspond with the tolerances observed within natural ranges of both species. $C$. intestinalis is a euryhaline species, reportedly within its native habitat tolerating salinities ranging from 12-40 (Dybern 1967; Carver et al. 2006; Therriault and Herborg 2008b). By contrast the invasive S. clava is rarely found below salinities of 20 (Lützen 1999; Davis et al. 2007; Davis and Davis 2008). However, this species has been known to survive short durations when subjected to salinities below 20, purportedly surviving for several days by closing siphons (Sims 1984; Lützen 1999). Similar behavioural responses have been observed in C. intestinalis which, in addition, has 
360

361

362

363

364

365

366

367

368

369

370

371

372

373

374

375

376

377

378

379

380

381

382

383

384

385

386

been shown to cease respiring during times of lowered salinity (Shumway 1978). This behavioural response of closing siphons is, perhaps, related to avoidance mechanisms similar to those employed by other species, such as bivalves closing shell valves (e.g. Davenport 1977) or burrowing behaviour in polychaetes (e.g. Shumway and Davenport 1977). This mechanism was not employed within our experiments for either species, however for both species cessation of response to siphonal stimuli did occur, indicating a severe stress response to decreased salinity. In mortality studies on tunicates, this lack of response is often recorded as an endpoint (Sims 1984; Peck et al. 2009; Zerebecki and Sorte 2011; Jofré Madariaga et al. 2014) however, as seen in this study, the lack of a response does not indicate death or cessation of respiration. Other factors should be taken into consideration to assess mortality or fitness of an individual, especially under salinity stress.

To our knowledge, only 2 previous studies have researched the effects of lowered salinities on the respiration of the two target species (ISI web of science search, accessed March 2018, using keyword combinations of: salinity|respiration|oxygen consumption - no further results were found when the search was expanded to include other ascidians). Of these, both studies present results contradictory to our own. Where we identified an increase in respiration due to the effects of lowered salinity, Shumway (1978) and Ai-Li et al. (2008) show decreasing salinities caused reductions in the respiration of $C$. intestinalis and $S$. clava respectively. However, these studies focus on shorter duration exposures than the results we present (6 hours and 2 hours respectively compared with our 24 hour exposure). Longer term subjection to lowered salinities could facilitate acclimation and a response related to longer term exposure. Kinne (1966) proposed 4 categories describing the varied physiological responses of organisms when exposed to changes in salinity, stating that metabolic rates will either be "(1) increased by subnormal salinities, and/or reduced in supranormal salinities, (2) increased both in sub- and supranormal salinities, (3) reduced both in sub- and supranormal salinities, (4) essentially unaffected." Within this study, our results correspond with categories 1 and 2 describing increases in metabolic response caused by subnormal salinities. This is a response typical of other euryhaline species (e.g. Kinne 1966; Roast et al. 1999; Ern et al. 2014). To compensate for increased stress, regulatory mechanisms (such as osmoregulation) come at a significant energetic cost 
387 (Rivera-Ingraham and Lignot 2017). In turn, this can lead to an elevated oxygen demand and

388 increased respiration rates (Rivera-Ingraham and Lignot 2017).

389 Previous experimental evidence suggests that impacts caused by decreased salinities would be lower

390 for invasive species (Lenz et al. 2011). While S. clava had a lower respiration rate than C. intestinalis

391 at all salinities, surprisingly we found limited evidence to suggest that, within the range tested,

392 hyposalinity had a greater negative impact on $C$. intestinalis. Furthermore, given that previous

393 evidence suggests the salinity tolerance range of $C$. intestinalis to be greater than S. clava (Dybern

394 1967; Lützen 1999; Carver et al. 2006; Davis et al. 2007), it is interesting to note that a behavioural

395 response (unresponsive to stimuli) was observed in C. intestinalis at higher salinities (lower stress).

396 Within this study we did not measure recovery, ultimately this could be a determining factor when

397 analysing the tolerance limits of either species.

398 Tolerance ranges can often vary among populations of the same species. Within the Baltic Sea,

399 Dybern (1967) noted the high tolerance of $C$. intestinalis to low salinities of 11 in regions that are

400 regularly subjected to these regimes. Similarly, Lützen (1999) noted that populations of S. clava

401 within Danish fjords are able to survive regular periodic drops below salinities of 20, tolerating

402 salinities documented to be lethal elsewhere. The individuals collected in this study were taken from a

403 marina which was in close proximity to the Penfeld River in Brest. This could facilitate regular

404 exposure to low salinities, especially after strong rainfall. Over generations, species have the ability to

405 adapt to new locations and conditions through natural selection and adaptive evolution (Colautti and

406 Lau 2015). This adaptive ability seen in invasive species makes them particularly problematic within

407 the marine environment. To fully appreciate the impact of invasive species, studies need to be

408 conducted on the resistance of species to environmental pressures within and among their native and

409 invasive ranges.

\section{$410 \quad$ 5. Conclusion}

411 We found that the invasive Styela clava displayed greater tolerance compared with Ciona intestinalis

412 to both increased temperatures and to decreased salinities, however limited differences in metabolic 
413

414

415

416

417

418

419

420

421

422

423

424

425

426

427

428

429

430

431

432

433

434

435

436

437

response between the two species were observed. This study is among the first to experimentally suggest upper limits on survival and metabolic response for either species to these common environmental stressors. This was due to limited prior experimental evidence for the newly taxonomically re-evaluated $C$. intestinalis and the invasive $S$. clava. As such this study offers insights into the mechanisms behind the successful ability shown in these species to become invasive worldwide. Human mediated dispersal of organisms is likely to select for the most tolerant, fast growing and adaptive species. These species must be able to survive transport and subsequently become established within an area to truly become invasive. Future threats from climate change will only exacerbate the spread of invasive species. The wide tolerance ranges displayed here by $S$. clava are typical of invasive species worldwide, and as such, these factors must be taken into consideration to understand how and where species invasions are likely to occur.

\section{$\underline{\text { Supplemental material }}$}

Table S1: Continuous water temperature data from 26/04/2017 - 03/10/2017, logged using HOBO data loggers recording temperature every 15 minutes and permanently fixed to floating structures from 3 locations within Château Marina, Brest, France.

\section{$\underline{\text { Acknowledgements }}$}

We are undoubtfully grateful to the Harbour Authority of the Château Marina in Brest for their authorisation in collection. We would like also to thank Jérôme Coudret and Mathieu Camusat for help with field collection, and Sophie Martin for help with the respiration measurements and analysis. We are also grateful to the 'Service Mer et Observation' and to the 'Centre de Ressources en Biologie Marine' of the Roscoff Biological Station which provided technical support for diving and algae culture respectively. This work was partly funded by the Region Bretagne under the SAD postdoctoral program 'Bzh-ITun' and the Conseil Departemental of Finistere postdoctoral program, both to JK (PI: CL).

\section{Compliance with ethical standards}


438 Funding: This work was partly funded by grants from the Region Bretagne under the SAD

439 postdoctoral program 'Bzh-ITun' and the Conseil Departemental of Finistere postdoctoral program,

440 both to Joseph Kenworthy (Principal Investigator: Christophe Lejeusne).

441 Conflict of interest: The authors declare no conflicts of interest.

442 Ethical approval: All applicable international, national, and/or institutional guidelines for the care and 443 use of animals were followed

\section{$444 \quad$ References}

Ai-Li J, Jin-Li G, Wen-Gui C, Chang-Hai W (2008) Oxygen consumption of the ascidian Styela clava in relation to body mass, temperature and salinity. Aquac Res 39:1562-1568. doi: $10.1111 / j .1365-2109.2008 .02040 . x$

Aldred N, Clare AS (2014) Mini-review: impact and dynamics of surface fouling by solitary and compound ascidians. Biofouling 12:259-70. doi: 10.1007/s10530-009-9571-8

Bouchemousse S, Bishop JDD, Viard F (2016a) Contrasting global genetic patterns in two biologically similar, widespread and invasive Ciona species (Tunicata, Ascidiacea). Sci Rep 6:24875. doi: $10.1038 /$ srep24875

Bouchemousse S, Lévêque L, Viard F (2016b) Do settlement dynamics influence competitive interactions between an alien tunicate and its native congener? Ecol Evol 7:200-213. doi: $10.1002 /$ ece 3.2655

Brunetti R, Gissi C, Pennati R, Caicci F, Gasparini F, Manni L (2015) Morphological evidence that the molecularly determined Ciona intestinalis type A and type B are different species: Ciona robusta and Ciona intestinalis. J Zool Syst Evol Res 53:186-193. doi: 10.1111/jzs.12101

Buizer DAG (1980) Explosive development of Styela clava Herdman, 1882, in the Netherlands after its introduction (Tunicata ascidiacea). Bull Zool Museum 7:181-183.

Butchart SHM, Walpole M, Collen B, van Strien A, Scharlemann JPW, Almond REA, Baillie JEM, 
Bomhard B, Brown C, Bruno J, Carpenter KE, Carr GM, Chanson J, Chenery AM, Csirke J, Davidson NC, Dentener F, Foster M, Galli A, Galloway JN, Genovesi P, Gregory RD, Hockings M, Kapos V, Lamarque J-F, Leverington F, Loh J, McGeoch MA, McRae L, Minasyan A, Morcillo MH, Oldfield TEE, Pauly D, Quader S, Revenga C, Sauer JR, Skolnik B, Spear D, Stanwell-Smith D, Stuart SN, Symes A, Tierney M, Tyrrell TD, Vie J-C, Watson R (2011) Global Biodiversity : Indicators of Recent Declines. Science 1164:1164-1169. doi: $10.1126 /$ science. 1187512

Carlisle DB (1954) Styela mammiculata n. sp. a new species of ascidian from the Plymouth area. J Mar Biol Assoc United Kingdom 33:329-334. doi: 10.1017/S0025315400008365

Carver CE, Mallet a L, Vercaemer B (2006) Biological Synopsis of the Solitary Tunicate Ciona intestinalis. Can Manuscr Rep Fish Aquat Sci No 2746:55.

Çinar ME (2016) The alien ascidian Styela clava now invading the Sea of marmara (Tunicata: Ascidiacea). Zookeys 2016:1-10. doi: 10.3897/zookeys.563.6836

Clarke C, Therriault T (2007) Biological synopsis of the invasive tunicate Styela clava (Herdman 1881). Can Manuscr Rep Fish Aquat Sci 2807 1-23.

Clarke Murray C, Therriault TW, Martone PT (2012) Adapted for invasion? Comparing attachment, drag and dislodgment of native and nonindigenous hull fouling species. Biol Invasions 14:16511663. doi: 10.1007/s10530-012-0178-0

Colautti RI, Lau JA (2015) Contemporary evolution during invasion: Evidence for differentiation, natural selection, and local adaptation. Mol Ecol 24:1999-2017. doi: 10.1111/mec.13162

Colautti RI, Bailey SA, Van Overdijk CDA, Amundsen K, MacIsaac HJ (2006) Characterised and projected costs of nonindigenous species in Canada. Biol Invasions 8:45-59. doi: 10.1007/s10530-005-0236-y

Cook EJ, Jenkins S, Maggs C, Minchin D, Mineur F, Nall C, Sewel J (2013) Impacts of Climate Change on non-native species. MCCIP Sci Rev 155-166. doi: 10.15414/raae.2013.16.02.24-39 
487

488

489

490

491

492

493

494

495

496

497

498

499

500

501

502

503

504

505

506

507

508

509

510

Davenport J (1977) A study of the effects of copper applied continuously and discontinuously to specimens of Mytilus edulis (L.) exposed to steady and fluctuating salinity levels. J Mar Biol Assoc United Kingdom 57:63. doi: 10.1017/S0025315400021238

Davis MH, Davis ME (2008) First record of Styela clava (Tunicata, Ascidiacea) in the Mediterranean region. Aquat Invasions 3:125-132. doi: 10.3391/ai.2008.3.2.2

Davis MH, Davis ME (2010) The impact of the ascidian Styela clava Herdman on shellfish farming in the Bassin de Thau, France. J Appl Ichthyol 26:12-18. doi: 10.1111/j.1439-0426.2010.01496.x

Davis MH, Lützen J, Davis ME (2007) The spread of Styela clava Herdman, 1882 (Tunicata, Ascidiacea) in European waters. Aquat Invasions 2:378-390. doi: 10.3391/ai.2007.2.4.6

De Rivera CE, Steves BP, Fofonoff PW, Hines AH, Ruiz GM (2011) Potential for high-latitude marine invasions along western North America. Divers Distrib 17:1198-1209. doi: 10.1111/j.1472-4642.2011.00790.x

Dukes JS, Mooney HA (1999) Does global change increase the success of biological invaders? Trends Ecol Evol 14:135-139. doi: 10.1016/S0169-5347(98)01554-7

Dybern BI (1965) The Life Cycle of Ciona intestinalis (L.) f. typica in Relation to the Environmental Temperature. Oikos 16:109-131. doi: 10.2307/3564870

Dybern BI (1967) The distribution and salinity tolerance of Ciona intestinalis (L.) F. typica with special reference to the waters around Southern Scandinavia. Ophelia 4:207-226.

Ern R, Huong DTT, Cong N V., Bayley M, Wang T (2014) Effect of salinity on oxygen consumption in fishes: A review. J Fish Biol 84:1210-1220. doi: 10.1111/jfb.12330

Gittenberger A, Van Der Stelt RC (2011) Artificial structures in harbors and their associated ascidian fauna. Aquat Invasions 6:413-420. doi: 10.3391/ai.2011.6.4.06

Halpern BS, Walbridge S, Selkoe KA, Kappel C V, Micheli F, D’Agrosa C, Bruno JF, Casey KS, Ebert C, Fox HE, Fujita R, Heinemann D, Lenihan HS, Madin EMP, Perry MT, Selig ER, 
511

512

513

514

515

516

517

518

519

520

521

522

523

524

525

526

527

528

529

530

531

532

533

534

Spalding M, Steneck R, Watson R (2008) A Global Map of Human Impact on Marine Ecosystems. Science 319:948-952. doi: 10.1126/science.1149345

Hellmann JJ, Byers JE, Bierwagen BG, Dukes JS (2008) Five potential consequences of climate change for invasive species. Conserv Biol 22:534-543. doi: 10.1111/j.1523-1739.2008.00951.x

IPCC (2013) Climate Change 2013: The Physical Science Basis. Contribution of Working Group I to the Fifth Assessment Report of the Intergovernmental Panel on Climate Change.

Jiang A li, Lin J, Wang C hai (2008) Physiological energetics of the ascidian Styela clava in relation to body size and temperature. Comp Biochem Physiol - A Mol Integr Physiol 149:129-136. doi: 10.1016/j.cbpa.2006.08.047

Jofré Madariaga D, Rivadeneira MM, Tala F, Thiel M (2014) Environmental tolerance of the two invasive species Ciona intestinalis and Codium fragile: their invasion potential along a temperate coast. Biol Invasions 16:2507-2527. doi: 10.1007/s10530-014-0680-7

Kang CK, Lee YJ, Han E, Park HJ, Yun SG, Lee WC (2015) Effects of temperature and body size on the physiological energetics of the stalked sea squirt Styela clava. J Exp Mar Bio Ecol 462:105112. doi: $10.1016 /$ j.jembe.2014.10.026

Kelley AL (2014) The role thermal physiology plays in species invasion. Conserv Physiol 2(1): cou045

Kinne O (1966) Physiological aspects of animal life in estuaries with special reference to salinity. Netherlands J Sea Res 3:222-244. doi: 10.1016/0077-7579(66)90013-5

Lagos ME, Barneche DR, White CR, Marshall DJ (2017) Do low oxygen environments facilitate marine invasions? Relative tolerance of native and invasive species to low oxygen conditions. Glob Chang Biol 23:2321-2330. doi: 10.1111/ijlh.12426

Lambert CC, Lambert G (1998) Non-indigenous ascidians in southern California harbors and marinas. Mar Biol 130:675-688. doi: 10.1007/s002270050289 
535

536

537

538

539

540

541

542

543

544

545

546

547

548

549

550

551

552

553

554

555

556

557

558

559

Lejeusne C, Chevaldonné P, Pergent-Martini C, Boudouresque CF, Pérez T (2010) Climate change effects on a miniature ocean: the highly diverse, highly impacted Mediterranean Sea. Trends Ecol Evol 25:250-260. doi: 10.1016/j.tree.2009.10.009

Lejeusne C, Latchere OO, Petit N, Rico C, Green AJ (2014) Do invaders always perform better? Comparing the response of native and invasive shrimps to temperature and salinity gradients in south-west Spain. Estuar Coast Shelf Sci 136:102-111. doi: 10.1016/j.ecss.2013.11.014

Lenz M, da Gama BAP, Gerner N V., Gobin J, Gröner F, Harry A, Jenkins SR, Kraufvelin P, Mummelthei C, Sareyka J, Xavier EA, Wahl M (2011) Non-native marine invertebrates are more tolerant towards environmental stress than taxonomically related native species: Results from a globally replicated study. Environ Res 111:943-952. doi: 10.1016/j.envres.2011.05.001

Lützen J (1999) Styela clava Herdman (Urochordata, Ascidiacea), a successful immigrant to North West Europe: ecology, propagation and chronology of spread. Helgoländer Meeresuntersuchungen 52:383-391. doi: 10.1007/BF02908912

Mack RN, Simberloff D, Londsdale WM, Evans H, Clout M, Bazzaz FA (2000) Biotic Invasions: Causes, Epidemiology, Global Consequences, and Control. Ecol Appl 10:689-710.

Marin MG, Bresson M, Beohi L, Brunetti R (1987) Thermo-haline tolerance of Ciona intestinalis (L, 1767) at different developmental stages. Cah Biol Mar 28:47-57.

Meehl GA (2004) More Intense, More Frequent, and Longer Lasting Heat Waves in the 21st Century. Science 305:994-997. doi: 10.1126/science.1098704

Newell RC, Branch GM (1980) The influence of temperature on the maintenance of metabolic energy balance in marine invertebrates. Adv Mar Biol 17:329-396. doi: 10.1016/S00652881(08)60304-1

Noisette F, Bordeyne F, Davoult D, Martin S (2016) Assessing the physiological responses of the gastropod Crepidula fornicata to predicted ocean acidification and warming. Limnol Oceanogr 61:430-444. doi: 10.1002/lno.10225 
560 Peck LS, Clark MS, Morley SA, Massey A, Rossetti H (2009) Animal temperature limits and 561 ecological relevance: Effects of size, activity and rates of change. Funct Ecol 23:248-256. doi: 10.1111/j.1365-2435.2008.01537.x

Pejchar L, Mooney HA (2009) Invasive species, ecosystem services and human well-being. Trends Ecol Evol 24:497-504. doi: 10.1016/j.tree.2009.03.016

Perkins-Kirkpatrick SE, Gibson PB (2017) Changes in regional heatwave characteristics as a function of increasing global temperature. Sci Rep 7:12256. doi: 10.1038/s41598-017-12520-2

Peters K, Sink K, Robinson T (2017) Raising the flag on marine alien fouling species. Manag Biol Invasions 8:1-11. doi: 10.3391/mbi.2017.8.1.01

Petersen JK, Riisgard HU (1992) Filtration capacity of the ascidian Ciona intestinalis and its grazing impact in a shallow fjord. Mar Ecol Prog Ser 88:9-17. doi: 10.3354/meps088009

Pimentel D, Zuniga R, Morrison D (2005) Update on the environmental and economic costs associated with alien-invasive species in the United States. Ecol Econ 52:273-288. doi: 10.1016/j.ecolecon.2004.10.002

R Core team (2015) R Core Team. R A Lang. Environ. Stat. Comput. R Found. Stat. Comput. , Vienna, Austria. ISBN 3-900051-07-0, URL http//www.R-project.org/. 55:275-286.

Rius M, Clusella-Trullas S, Mcquaid CD, Navarro RA, Griffiths CL, Matthee CA, Von der Heyden S, Turon X (2014) Range expansions across ecoregions: Interactions of climate change, physiology and genetic diversity. Glob Ecol Biogeogr 23:76-88. doi: 10.1111/geb.12105

Rivera-Ingraham GA, Lignot J-H (2017) Osmoregulation, bioenergetics and oxidative stress in coastal marine invertebrates: raising the questions for future research. J Exp Biol 220:1749-1760. doi: $10.1242 /$ jeb. 135624

Roast SD, Jones MB, Widdows J (1999) Respiratory responses of the estuarine mysid Neomysis integer (Peracarida: Mysidacea) in relation to a variable environment. Mar Biol 133:643-649. doi: $10.1007 / \mathrm{s} 002270050504$ 
585

586

587

588

589

590

591

592

593

594

595

596

597

598

599

600

601

602

603

604

605

606

607

608

Shumway SE (1978) Respiration, pumping activity and heart rate in Ciona intestinalis exposed to fluctuating salinities. Mar Biol 48:235-242. doi: 10.1007/BF00397150

Shumway SE, Davenport J (1977) Some aspects of the physiology of Arenicola marina to fluctuating salinities. J Mar Biol Assoc UK 57:907-924.

Sims LL (1984) Osmoregulatory capabilities of three macrosympatric stolidobranch ascidians, Styela clava Herdman, S. plicata (Lesueur), and S. montereyensis (Dall). J Exp Mar Bio Ecol 82:117129. doi: 10.1016/0022-0981(84)90098-4

Smale DA, Yunnie ALE, Vance T, Widdicombe S (2015) Disentangling the impacts of heat wave magnitude, duration and timing on the structure and diversity of sessile marine assemblages. PeerJ 3:e863. doi: 10.7717/peerj.863

Sorte CJB, Fuller A, Bracken MES (2010) Impacts of a simulated heat wave on composition of a marine community. Oikos 119:1909-1918. doi: 10.1111/j.1600-0706.2010.18663.x

Therriault TW, Herborg L (2008a) A qualitative biological risk assessment for vase tunicate Ciona interstinalis in Canadian waters: using expert knowledge. ICES J Mar Sci 65:781-787. doi: 10.1093/icesjms/fsn059

Therriault TW, Herborg L (2008b) Predicting the potential distribution of the invasive tunicate Ciona intestinalis in Canadian waters : informing a risk assessment. ICES J Mar Sci 65:788-794. doi: 10.1093/icesjms/fsn054

Vercaemer B, Sephton D, Nicolas JM, Howes S, Keays J (2011) Ciona intestinalis environmental control points: Field and laboratory investigations. Aquat Invasions 6:477-490. doi: 10.3391/ai.2011.6.4.13

Warren CE, Davis GE (1967) Laboratory studies on the feeding, bioenergetics, and growth of fish. In: Gerking SD (ed) The Biological Basis of Freshwater Fish Production. Blackwell Scientific Publications, Oxford, pp 175-214 

species success. PLoS One. doi: 10.1371/journal.pone.0014806

611 Zhan A, MacIsaac HJ, Cristescu ME (2010) Invasion genetics of the Ciona intestinalis species 612 complex: From regional endemism to global homogeneity. Mol Ecol 19:4678-4694. doi:

613 10.1111/j.1365-294X.2010.04837.x

614 